\title{
Acute metabolic response to fasted and postprandial exercise
}

This article was published in the following Dove Press journal:

International Journal of General Medicine

13 August 2015

Number of times this article has been viewed

Filipe Dinato de Lima ${ }^{1,2}$

Ana Luiza Matias Correia'

Denilson da Silva Teixeira ${ }^{2}$

Domingos Vasco da Silva

$\mathrm{Neto}^{2}$

Ítalo Sávio Gonçalves

Fernandes ${ }^{2}$

Mário Boratto Xavier Viana ${ }^{2}$

Mateus Petitto ${ }^{2}$

Rodney Antônio da Silva

Sampaio ${ }^{2}$

Sandro Nobre Chaves ${ }^{2}$

Simone Teixeira Alves ${ }^{2}$

Renata Aparecida Elias

Dantas $^{2}$

Márcio Rabelo Mota

'University of Brasília, Brasília, DF, Brazil; ${ }^{2}$ Universitary Center of Brasília (UniCEUB), Brasília, DF, Brazil
Correspondence: Filipe Dinato de Lima Universitary Center of Brasília (UniCEUB), SEPN 707/907, Asa Norte, 70790-075, Brasilia, Brazil

Tel +556184355610

Email fdinatolima@gmail.com
Abstract: The aim of this study was to analyze the acute metabolic response to exercise in fasting and postprandial. For this, ten individuals were submitted to an incremental treadmill test, with an initial speed of 5 and $1 \mathrm{~km} / \mathrm{h}$ increments every minute, with no inclination, and a body composition assessment. After this 1st day, all volunteers were submitted to two experimental procedures (fasting and postprandial), with an aerobic exercise performed for 36 minutes at $65 \%$ of maximal oxygen consumption. At postprandial procedure, all subjects ingested a breakfast containing $59.3 \mathrm{~g}$ of carbohydrate (76.73\%), $9.97 \mathrm{~g}$ of protein $(12.90 \%), 8.01 \mathrm{~g}$ of lipids $(10.37 \%)$, with a total energy intake of $349.17 \mathrm{kcal}$. An analysis of plasma concentration of triglycerides, lactate, and glucose was performed in two stages: before and after exercise. The Shapiro-Wilk test was used to verify the normality of the data. For analysis of glucose concentration, plasma lactate, and triglycerides, we used a repeated measures analysis of variance factorial $2 \times 2$, with Bonferroni multiple comparison test. The significance level of $P<0.05$ was adopted. The results indicated a maintenance level of glucose at fasting and a decrease in glucose concentration at postprandial exercise. Both conditions increase plasma lactate. Triglycerides also increased in the two experimental conditions; however, after exercise fasting, the increase was significantly higher than in the postprandial exercise. These data suggest that both exercises could increase plasma lactate and triglycerides. However, exercise performed in fasting condition decreases glucose concentration and increases triglycerides, even more than postprandial exercise.

Keywords: aerobic exercise, energy metabolism, blood glucose, lactic acid, triglycerides

\section{Introduction}

Exercise performed in fasting condition is used as a strategy to lose weight because it greatly enhances aerobic metabolism, promoting fat oxidation during activity ${ }^{1}$ due to the decrease in muscle glycogen supply and limited stimulation of glycogenolysis. In addition, it models the hormonal response during and after exercise. ${ }^{2-4}$ In exercise performed in fasting condition, the respiratory exchange ratio is maintained low, indicating a greater mobilization of fat as an energy source, due to the low supply of glycogen. ${ }^{5,6}$ However, postprandial exercise seems to promote a greater activation of metabolism in subsequent hours and to increase maximal oxygen consumption ( $\left.\mathrm{VO}_{2} \max \right)$ for hours after activity. ${ }^{5}$ The changes in metabolic parameters after exercise, compared with the two conditions studied, indicate that exercise after feeding promotes a contradictory increase in fat oxidation, especially after stopping activity. ${ }^{3,5}$

The literature shows much diversity among studies investigating the influence of fasting on metabolic parameters.

An early response to fasting is the mobilization of triglycerides reserves present in adipocytes, in addition to decrease in the metabolism of carbohydrates in order to 
maintain the blood glucose concentration for supply to the central nervous system and red blood cells. ${ }^{4}$ The maintenance of blood glucose concentration even in fasting is due to the balance between the hormones insulin and glucagon, in addition to the catecholamine secretion during prolonged submaximal exercise. ${ }^{7}$ During activity, the secretion of catecholamines and cortisol and the increase in glucagon concentration promote the hepatic glycogen degradation and the decrease in insulin resistance, even in vigorous exercise. ${ }^{8}$ Moreover, the ingestion of a large amount of glucose before and during aerobic exercise does not seem to interfere on the contribution of carbohydrates and fats to the metabolism, although positively influencing the aerobic performance. ${ }^{9}$ De Bock et $\mathrm{al}^{10}$ affirm that metabolic adaptations to exercise performed in fasting condition and after carbohydrate intake are similar. However, training conducted in a fasting state seems to promote an increase in the amount of muscle glycogen, enhance peak $\mathrm{VO}_{2}$, and improve the maximum power. $^{11}$

Information regarding exercise performed in fasting condition does not indicate any agreement in relation to its effects on the metabolism of fats and carbohydrates. The performance of postprandial exercise seems to favor the metabolism of fats for 24 hours after the activity, ${ }^{12}$ while exercise performed in a fasted state seems to provide greater mobilization of fat during practice..$^{5,6}$ The concentration of triglycerides is an important indicator of fat metabolism and lipolysis. ${ }^{13}$ Furthermore, the low availability of muscle glycogen and the increase in oxidative metabolism in fasted exercise $^{2-4}$ can promote lower blood lactate production and a reduced metabolic acidosis.

However, the response of blood glucose, blood lactate, and triglycerides to exercise performed in both fasting and postprandial conditions is not explicit in the literature, and this understanding is fundamental to assess the influence of fasting on metabolism. Thus, the aim of this study was to analyze the metabolic response to exercise (36 minutes of aerobic exercise on the treadmill at $65 \%$ of $\mathrm{VO}_{2} \max$ ) performed on fasting and after feeding.

\section{Methods}

\section{Subjects}

The study was approved by the Research Ethics Committee of the University Center of Brasília, Brazil. Ten subjects aged between 20 and 30 years participated in the study. All participants provided informed consent in writing, agreeing with all the procedures, and were nonsmokers, with no cardiovascular, metabolic, or musculoskeletal diseases that could affect the performance on procedures, and practiced regular physical activity for at least 12 months. The sample characteristics (mean \pm standard deviation) are as follows: age, $25.50 \pm 2.22$ years; body mass, $88.43 \pm 10.71 \mathrm{~kg}$; height, $1.80 \pm 0.06 \mathrm{~m}$; body mass index, $27.11 \pm 4.28 \mathrm{~kg} / \mathrm{m}^{2}$; body fat percentage estimated, $22.39 \% \pm 8.26 \%$; maximal oxygen consumption estimated, $48.75 \pm 6.67 \mathrm{~mL} / \mathrm{kg} / \mathrm{min}$.

\section{Evaluation}

Volunteers visited the place for procedures on 3 different days. The researchers requested them not to consume alcoholic drinks and stimulants as well as not to perform physical activity during the research. On the 1st day, the volunteers were subjected to preliminary anthropometric assessment and assessment of maximal oxygen consumption, and they completed the questionnaires that indicated possible pathologies, level of physical activity, and eating habits. The assessment of body mass was conducted on a Filizola digital balance (Filizola SA, Sao Paulo, Brazil), with a capacity of $150 \mathrm{~kg}$ and an accuracy of $50 \mathrm{~g}$. Height was measured with a Sanny stadiometer (American Medical do Brasil Ltda., São Bernardo do Campo, Brazil), with a capacity of $210 \mathrm{~cm}$ and a precision of $1 \mathrm{~mm}$. From these measurements, body mass index was calculated. Body composition was estimated through skinfold with a Cescorf adipometer (Cescorf Equipamentos Esportivos Ltda., Porto Alegre, Brazil), using protocol of seven skinfolds proposed by Jackson and Pollock. ${ }^{14}$

The maximal oxygen uptake was estimated using a maximal incremental nonincline treadmill test (RUN 700, Techno Gym Ltda., Rio de Janeiro, Brazil). The protocol consisted of an initial speed of $5 \mathrm{~km} / \mathrm{h}$, with increments of $1 \mathrm{~km} / \mathrm{h}$ every 1 minute. It is understood that, with this protocol, the muscle fatigue caused by inclinations on the treadmill was avoided, favoring the execution of the maximal test, with no underestimation of it. In this sense, stages of 1-minute duration promoted quick increments and a higher $\mathrm{VO}_{2}$, as proposed by Machado et al. ${ }^{15}$ This protocol was first used by Lima et al. ${ }^{16}$ The assessment was interrupted whenever the individual demonstrated volitional exhaustion or the maximum heart rate estimated by the formula 220 minus age, proposed by Karvonen ${ }^{17}$ was achieved. To estimate $\mathrm{VO}_{2}$ max, we used Ventilometer $\mathrm{VO}_{2}$ ProFitness (CEFISE Biotecnologia Esportiva, Nova Odessa, Brazil).

\section{Experimental protocol}

Participants performed two exercise sessions (fasting and postprandial), randomized and separated by 72 hours. Each session occurred early in the morning (7 am) and 
was preceded by an overnight fast of at least 10 hours. On both days, the volunteers performed aerobic exercise on the treadmill without gradient for 36 minutes at the intensity of $65 \%$ of $\mathrm{VO}_{2}$ max. The length of the exercise was based on the study of Paoli et al. ${ }^{5}$ However, that study investigated the intensity of $65 \%$ of heart rate reserve. The researchers of this study aimed to investigate a higher intensity, believing that this would promote greater physiological adaptations.

The running speed was calculated according to the formula proposed by American College of Sports Medicine: ${ }^{18}$

$$
\mathrm{VO}_{2}=3.5+(0.2 \times \text { speed })+(0.9 \times \text { speed } \times \% \text { grade })
$$

To perform the exercise fasting, individuals remain at rest for 15 minutes after arrival at the laboratory, before performing the race. For the exercise after feeding, the individuals were provided a meal containing yogurt, whole cookie, banana, and cereal bar, containing $59.3 \mathrm{~g}$ of carbohydrate $(76.73 \%), 9.97 \mathrm{~g}$ of protein $(12.90 \%), 8.01 \mathrm{~g}$ of lipids $(10.37 \%)$, with a total energy of $349.17 \mathrm{kcal}$. After feeding, the volunteers remained at rest for 15 minutes before the beginning of the exercise as well as fasting.

In the two experimental situations, the two plasma samples of the volunteers, obtained immediately after 15 minutes of rest and immediately after the exercise, were used for the determination of glucose concentration, plasma lactate, and triglycerides. The blood was collected through a puncture of the distal phalanx of the ring finger of the nondominant hand. Before the collection, the puncture site was aseptically cleaned with $70 \%$ alcohol. The first drop of blood was discarded, then a sample of $3 \mu \mathrm{L}$ of blood was collected, which was analyzed using an Accu-Chek Performa glucose monitor (Roche Diagnostics, São Paulo, Brazil), a lactate monitor Accutrend Plus (Roche Diagnostics) validated by Perez et al, ${ }^{19}$ and a triglycerides monitor Accutrend Plus (Roche Diagnostics).

\section{Statistical analyses}

Data were analyzed using the statistical software SPSS version 21.0 for OSX (SPSS Inc., Somers, NY, USA). Data normality was verified by the Shapiro-Wilk test. Repeated measures analysis of variance $2 \times 2$ factorial (status $\times$ moment) was used to evaluate the concentration of lactate, glucose, and triglycerides before and after exercise in the two experimental conditions. The Bonferroni multiple comparison test was used when significant differences were found as well as interactions between the effects. The significance level of $P<0.05$ was adopted. Data were expressed in the results, tables, and graphs as mean \pm standard deviation.

\section{Results}

The participants performed the maximum incremental test to determine the $\mathrm{VO}_{2} \max$ in $11.25 \pm 2.05$ minutes. The estimated relative $\mathrm{VO}_{2} \max$ was $48.75 \pm 6.67 \mathrm{~mL} / \mathrm{kg} / \mathrm{min}$. The average speed of running performed in the two experimental conditions was $8.54 \pm 1.12 \mathrm{~km} / \mathrm{h}$.

Glucose concentration showed no significant difference in fasting (91.30 \pm 6.23 vs $96.32 \pm 6.84 \mathrm{mg} / \mathrm{dL} ; P=0.083)$. However, after the postprandial exercise, there was a significant reduction in blood glucose $(120.40 \pm 12.64$ vs $103.89 \pm 8.25$ $\mathrm{mg} / \mathrm{dL} ; P=0.005)$. The glucose concentration showed a significant difference between pre-exercise in fasting and postprandial (91.30 \pm 6.23 vs $120.40 \pm 12.64 \mathrm{mg} / \mathrm{dL} ; P=0.0001)$ and between postexercise in fasting and postprandial (96.32 \pm 6.84 vs $103.89 \pm 8.25 \mathrm{mg} / \mathrm{dL} ; P=0.009)$. The behavior of glycemia in both experimental conditions is shown in Figure 1. The plasma lactate concentration shows a significant increase in fasting $(1.75 \pm 0.62 \mathrm{vs} 4.10 \pm 1.40 \mathrm{mmol} / \mathrm{L} ; P=0.0001)$ and postprandial exercise $(1.85 \pm 0.77$ vs $3.51 \pm 1.43 \mathrm{mmol} / \mathrm{L}$; $P=0.0001)$. The behavior of the plasma lactate concentration in the two experimental conditions is shown in Figure 2. The concentration of triglycerides increased after exercise in both the fasting $(106.51 \pm 13.39$ vs $153.30 \pm 37.32 \mathrm{mg} / \mathrm{dL}$; $P=0.005)$ and the postprandial exercise $(99.66 \pm 20.21$ vs $117.55 \pm 26.14 \mathrm{mg} / \mathrm{dL} ; P=0.017)$. There was also a difference between the concentrations of triglycerides after exercise in the fasting and postprandial conditions $(153.30 \pm 37.32$ vs $117.55 \pm 26.14 \mathrm{mg} / \mathrm{dL} ; P=0.012)$. The behavior of triglycerides in both protocols is shown in Figure 3.

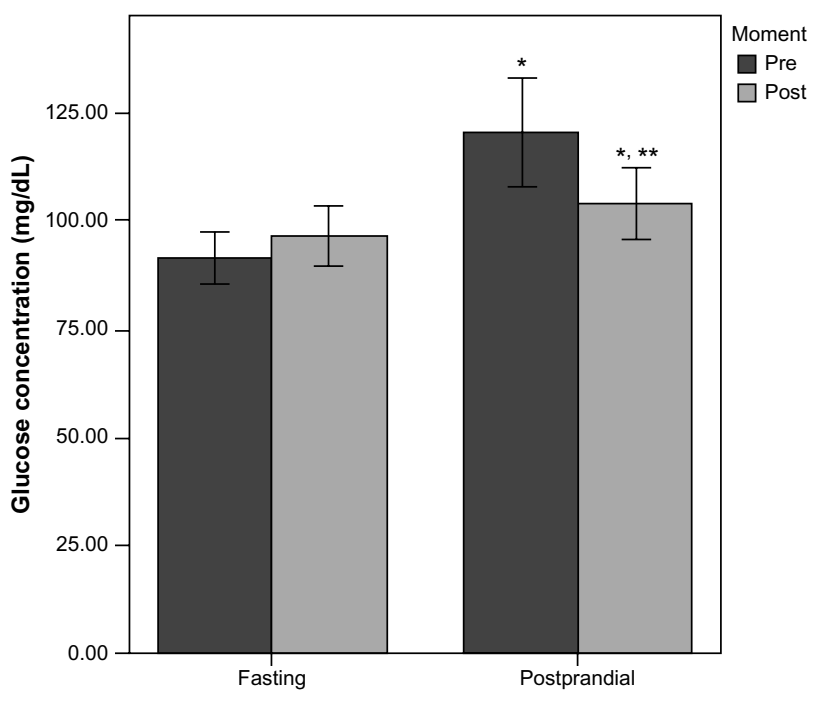

Figure I Glucose concentration in response to both types of exercise (fasting and postprandial) measured before and immediately after.

Notes: $* P<0.05$ between pre- and postexercise. $* * P<0.05$ between fasting and postprandial. 


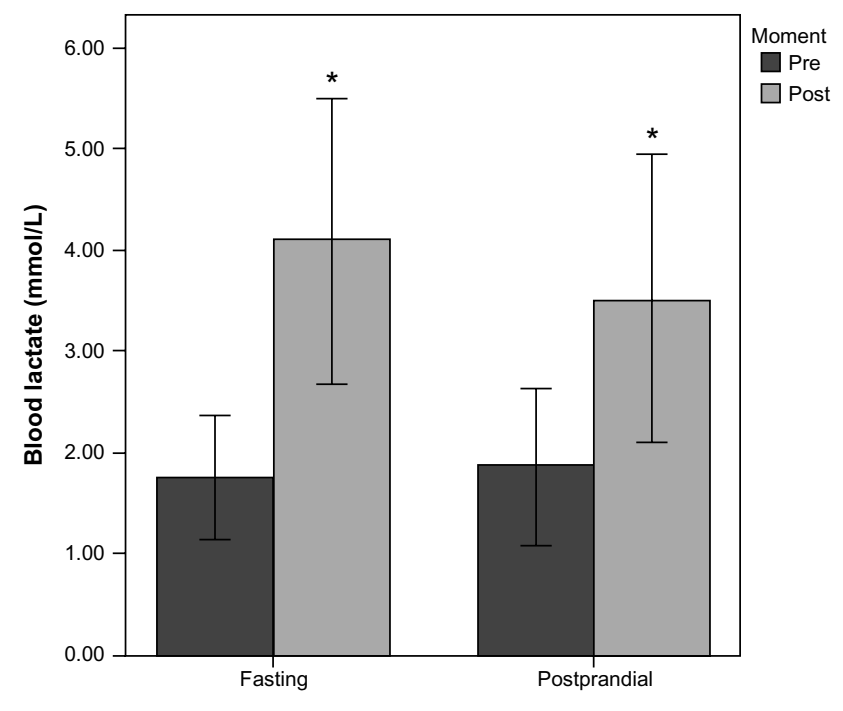

Figure 2 Blood lactate concentration in response to both types of exercise (fasting and postprandial) measured before and immediately after.

Note: $* P<0.05$ between pre- and postexercise.

\section{Discussion}

This study aimed to analyze the response of glucose concentration, plasma lactate, and triglycerides to exercise in fasting and postprandial conditions of 36 minutes' duration and with an intensity of $65 \% \mathrm{VO}_{2}$ max. The results showed a maintenance of glucose concentration in the case of exercise fasting and a significant reduction in glucose concentration in the postprandial period. The lactate concentration increased compared with the rest in both conditions, with no difference between them. Triglycerides also increased in the two experi-

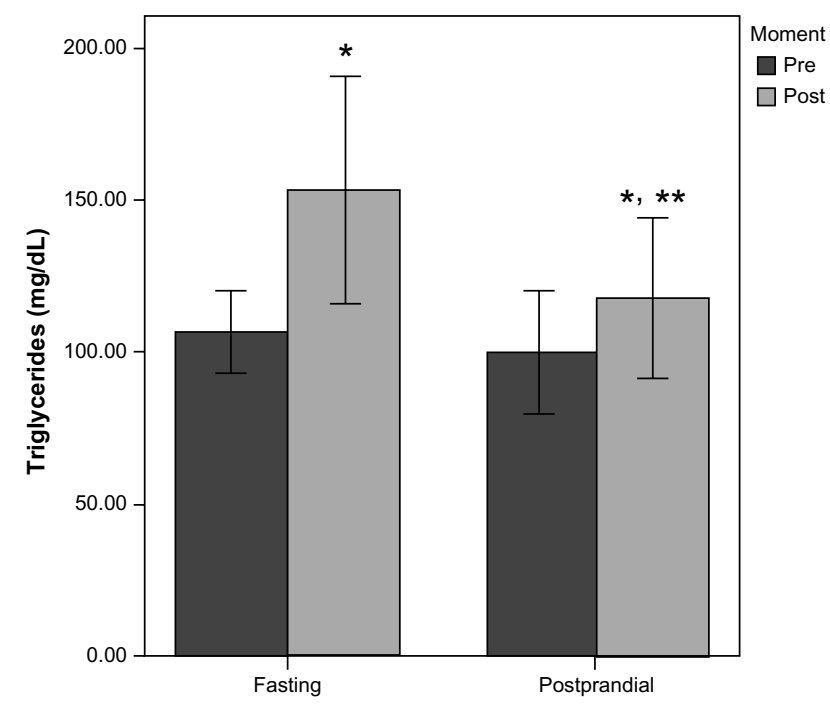

Figure 3 Triglycerides concentration in response to both types of exercise (fasting and postprandial) measured before and immediately after.

Notes: $* P<0.05$ between pre- and postexercise. $* * P<0.05$ between fasting and postprandial. mental conditions, though they were significantly higher after exercise fasting than in the case of postprandial exercise.

The behavior of blood glucose during submaximal exercise is mediated by insulin and glucagon response, beyond the influence of cortisol and catecholamines. During exercise, the increase in cortisol followed by glucagon stimulates gluconeogenesis and glycogenolysis, while the decrease in insulin concentration increases the sensitivity of the liver to glucagon, due to the increase in the number of receptors. ${ }^{7,8}$ Insulin concentration is reduced during moderate exercise $\left(60 \% \mathrm{VO}_{2} \mathrm{max}\right)$, while the increased sensitivity of glucagon in the liver results in the production of glucose. ${ }^{20}$ Adams $^{20}$ argued that glucose production by the liver is stimulated by catecholamines after 2 hours of exercise. However, Lima et $\mathrm{al}^{16}$ showed a significant increase in glucose concentration after the maximal test without gradient, with an average of 8.46 minutes.

Glucose concentration is influenced by exercise intensity. According to Thompson et al, ${ }^{8}$ blood glucose is maintained constant even with strenuous exercise, while Simoes et al ${ }^{21}$ show the behavior of glycemia during a test with progressive increases in intensity, indicating a decrease in the blood glucose concentration phase, a transition point referred to as glucose threshold, and a blood glucose elevation phase.

In this study, blood glucose remains constant during exercise fasting, probably due to the release of glucose by the liver via glycogenolysis and gluconeogenesis, stimulated by glucagon, catecholamines, and cortisol. In the fasting state, cortisol rises considerably, stimulating the release of glucagon and reducing the sensitivity of the liver to this hormone. ${ }^{2,4}$ Glucose concentration in the postprandial exercise was reduced due to the release of insulin stimulated by carbohydrate intake. ${ }^{7,20,22}$ Thus, the glucose present in the blood was used as fuel without having to resort to the liver glycogen. In this sense, not only intensity, type, and duration of exercise but also carbohydrate intake before exercise seems to affect the behavior of blood glucose. ${ }^{23,24}$

The plasma lactate concentration increases significantly in the two experimental conditions, with no differences between them. The $4 \mathrm{mmol} / \mathrm{L}$ lactate concentration value represents the maximum exercise intensity at which blood lactate is maintained stable, at which the glycolytic production rate is equalized with the conversion rate to pyruvate in the presence of oxygen, ${ }^{25}$ in addition to a proportional reduction in the concentration of bicarbonate responsible for the buffering of this metabolite. ${ }^{26}$ After hitting this threshold, the glycolysis process is powered, resulting in increased plasma lactate 
concentration, metabolic acidosis, and an increase in carbon dioxide production $\left(\mathrm{VCO}_{2}\right){ }^{26}$

Lactate is a result of dissociation of lactic acid with the production of hydrogen ions $\left(\mathrm{H}^{+}\right)$. This metabolite has little effect on muscle activity; however, the $\mathrm{H}^{+}$accumulation causes metabolic acidosis, inducing fatigue by inhibition of glycolytic metabolism, with inactivation of enzymes such as glycogen phosphorylase and phosphofructokinase and activation of nerves of groups III and IV of the afferent pathways, increasing the feeling of discomfort. ${ }^{27}$

In this study, the intensity of exercise selected by the authors seems to be sufficient to stimulate the glycolytic metabolism, since the lactate production was enhanced to values above the threshold. ${ }^{26}$ Furthermore, the influence of catecholamine secretion in lactate kinetics ${ }^{22}$ is crucial to explain the behavior of this metabolite after the two experimental conditions studied here. However, it was not possible to identify differences in lactate concentration between the protocols despite the hormonal difference between the performance of exercise in fasting and postprandial conditions.

An important result of this study was the significant increase in triglycerides in both situations. The behavior of the triglyceride concentration in blood plasma is controversial, since several studies have demonstrated a reduction in their levels during and after exercise. ${ }^{28-31}$ However, the enhancement of lipolysis seems to occur during physical activity, generating an increase in plasma triglyceride concentration, and consequently its subcomponents, glycerol and free fatty acids. ${ }^{32,33}$ The increase in lipolysis rate is due to the accentuated catecholamine secretion in addition to a higher sensitivity of adipose tissue to these hormones generated by the exercise. ${ }^{34}$ The stimulation of the release of triglycerides by increased secretion of epinephrine and norepinephrine helps explain the higher rate of lipolysis of the exercise in the fasting state, since the hormonal response of this protocol is increased. ${ }^{1,2,4}$

The triglycerides concentration can be affected by other factors besides lipolysis stimulation. The reduction of triglyceride concentration may occur due to the decrease in production of hepatic very-low density lipoprotein or lipoprotein lipase response, ${ }^{35}$ as well as the activity of chylomicrons. ${ }^{36}$ The behavior of triglycerides after exercise is influenced by the level of training of individuals, providing higher releases in trained individuals. ${ }^{37}$ This relationship seems to be favorable to the subjects in the study because they were all regular physical activity practitioners. Therefore, these results cannot be generalized to a different population.
This study has some limitations. The study population was young, trained, and had no diseases. So the results should not be generalized to people with diseases such as diabetes and obesity, or to women and the elderly. The study exercise protocol consisted of 36 minutes at $65 \%$ of $\mathrm{VO}_{2} \max$; however, it is known that the response of blood glucose, blood lactate, and triglycerides is dependent on the intensity, duration, and type of exercise. Thus, the results should not be generalized to other activities. Further studies should be conducted to investigate the metabolic responses to different types of exercise, with different intensities and durations. Finally, the behavior of glucose may be significantly influenced by the carbohydrates intake. Thus, the intake of carbohydrates with different glycemic index values and its influence on response to exercise should be investigated.

\section{Conclusion}

In summary, exercise in the fasting state performed for 36 minutes at $65 \%$ of $\mathrm{VO}_{2}$ max cannot significantly alter blood glucose, while feeding increases resting levels and modifies the response of glucose to exercise. The two experimental conditions promoted a significant increase in blood lactate values considered above lactate threshold. However, feeding does not influence the lactate production since there was no difference between the two protocols. The plasma triglyceride concentration suffered elevation in both the procedures; however, fasting promoted greater release, showing an increase in lipolysis generated by this protocol.

\section{Disclosure}

The authors report no conflicts of interest in this work.

\section{References}

1. Shimada K, Yamamoto Y, Iwayama K, et al. Effects of post-absorptive and postprandial exercise on $24 \mathrm{~h}$ fat oxidation. Metabolism. 2013;62(6): 793-800.

2. De Bock K, Richter EA, Russell AP, et al. Exercise in the fasted state facilitates fibre type-specific intramyocellular lipid breakdown and stimulates glycogen resynthesis in humans. J Physiol. 2005;564(Pt 2):649-660.

3. Bennard P, Doucet E. Acute effects of exercise timing and breakfast meal glycemic index on exercise-induced fat oxidation. Appl Physiol Nutr Metab. 2006;31(5):502-511.

4. Maughan RJ, Fallah J, Coyle EF. The effects of fasting on metabolism and performance. Br J Sports Med. 2010;44(7):490-494.

5. Paoli A, Marcolin G, Zonin F, Neri M, Sivieri A, Pacelli QF. Exercising fasting or fed to enhance fat loss? Influence of food intake on respiratory ratio and excess postexercise oxygen consumption after a bout of endurance training. Int J Sport Nutr Exerc Metab. 2011;21(1):48-54.

6. Deighton K, Zahra JC, Stensel DJ. Appetite, energy intake and resting metabolic responses to 60 min treadmill running performed in a fasted versus a postprandial state. Appetite. 2012;58(3):946-954.

7. Goodwin ML. Blood glucose regulation during prolonged, submaximal, continuous exercise: a guide for clinicians. J Diabetes Sci Technol. 2010;4(3):694-705. 
8. Thompson PD, Crouse SF, Goodpaster B, Kelley D, Moyna N, Pescatello L. The acute versus the chronic response to exercise. Med Sci Sports Exerc. 2001;33(6 Suppl):S438-S445.

9. Febbraio MA, Chiu A, Angus DJ, Arkinstall MJ, Hawley JA. Effects of carbohydrate ingestion before and during exercise on glucose kinetics and performance. J Appl Physiol (1985). 2000;89(6):2220-2226.

10. De Bock K, Derave W, Eijnde BO, et al. Effect of training in the fasted state on metabolic responses during exercise with carbohydrate intake. J Appl Physiol (1985). 2008;104(4):1045-1055.

11. Stannard SR, Buckley AJ, Edge JA, Thompson MW. Adaptations to skeletal muscle with endurance exercise training in the acutely fed versus overnight-fasted state. J Sci Med Sport. 2010;13(4):465-469.

12. Barwell ND, Malkova D, Leggate M, Gill JM. Individual responsiveness to exercise-induced fat loss is associated with change in resting substrate utilization. Metabolism. 2009;58(9):1320-1328.

13. Herd SL, Kiens B, Boobis LH, Hardman AE. Moderate exercise, postprandial lipemia, and skeletal muscle lipoprotein lipase activity. Metabolism. 2001;50(7):756-762.

14. Jackson AS, Pollock ML. Generalized equations for predicting body density of men. Br J Nutr. 1978;40(3):497-504.

15. Machado FA, Kravchychyn AC, Peserico CS, da Silva DF, Mezzaroba PV. Effect of stage duration on maximal heart rate and post-exercise blood lactate concentration during incremental treadmill tests. J Sci Med Sport. 2013;16(3):276-280.

16. Lima FD, Oliveira RJ, Correia ALM, Trindade ES, Dantas RAE, Mota MR. Glicemic and blood lactate response to maximal incremental treadmill test. Int J Sports Sci. 2015;5(2):59-64.

17. Karvonen MJ. The effects of training on heart rate. A longitudinal study. Ann Med Exp Biol Fenn. 1957;35:307-315.

18. American College of Sports Medicine Association. ACSM's Guidelines for Exercise Testing and Prescription. Philadelphia, PA: Lippincott Williams \& Wilkins; 2013.

19. Perez EH, Dawood H, Chetty U, Esterhuizen TM, Bizaare M. Validation of the Accutrend lactate meter for hyperlactatemia screening during antiretroviral therapy in a resource-poor setting. Int J Infect Dis. 2008; 12(5):553-556.

20. Adams OP. The impact of brief high-intensity exercise on blood glucose levels. Diabetes Metab Syndr Obes. 2013;6:113-122.

21. Simoes HG, Campbell CS, Kushnick MR, et al. Blood glucose threshold and the metabolic responses to incremental exercise tests with and without prior lactic acidosis induction. Eur J Appl Physiol. 2003;89(6):603-611.

22. Brooks GA, Wolfel EE, Butterfield GE, et al. Poor relationship between arterial [lactate] and leg net release during exercise at 4,300 $\mathrm{m}$ altitude. Am J Physiol. 1998;275(4 Pt 2):R1192-R1201.
23. Awobajo FO, Olawale OA, Bassey S. Changes in blood glucose, lipid profile and antioxidant activities in trained and untrained adult male subjects during programmed exercise on the treadmill. Nig $Q J$ Hosp Med. 2013;23(2):117-124.

24. Colberg SR, Hernandez MJ, Shahzad F. Blood glucose responses to type, intensity, duration, and timing of exercise. Diabetes Care. 2013;36(10):e177.

25. Beneke R. Training at lactate threshold: science based concept or irrational myth? J Sports Med Doping Stud. 2012;2(3):2.

26. Older P. Anaerobic threshold, is it a magic number to determine fitness for surgery? Perioper Med (Lond). 2013;2:2.

27. Westerblad H, Allen DG, Lannergren J. Muscle fatigue: lactic acid or inorganic phosphate the major cause? News Physiol Sci. 2002;17:17-21.

28. Cullinane E, Siconolfi S, Saritelli A, Thompson PD. Acute decrease in serum triglycerides with exercise: is there a threshold for an exercise effect? Metabolism. 1982;31(8):844-847.

29. Grandjean PW, Crouse SF, Rohack JJ. Influence of cholesterol status on blood lipid and lipoprotein enzyme responses to aerobic exercise. J Appl Physiol (1985). 2000;89(2):472-480.

30. Sondergaard E, Rahbek I, Sorensen LP, et al. Effects of exercise on VLDL-triglyceride oxidation and turnover. Am J Physiol Endocrinol Metab. 2011;300(5):E939-E944.

31. Franklin BA, Durstine JL, Roberts CK, Barnard RJ. Impact of diet and exercise on lipid management in the modern era. Best Pract Res Clin Endocrinol Metab. 2014;28(3):405-421.

32. Romijn JA, Coyle EF, Sidossis LS, et al. Regulation of endogenous fat and carbohydrate metabolism in relation to exercise intensity and duration. Am J Physiol. 1993;265(3 Pt 1):E380-E391.

33. Johnson NA, van Overbeek D, Chapman PG, Thompson MW, Sachinwalla T, George J. Effect of prolonged exercise and pre-exercise dietary manipulation on hepatic triglycerides in trained men. Eur J Appl Physiol. 2012;112(5):1817-1825.

34. Bahr R, Hansson P, Sejersted OM. Triglyceride/fatty acid cycling is increased after exercise. Metabolism. 1990;39(9):993-999.

35. Gill JM, Al-Mamari A, Ferrell WR, et al. Effects of a moderate exercise session on postprandial lipoproteins, apolipoproteins and lipoprotein remnants in middle-aged men. Atherosclerosis. 2006;185(1):87-96.

36. Potts JL, Fisher RM, Humphreys SM, Coppack SW, Gibbons GF, Frayn KN. Peripheral triacylglycerol extraction in the fasting and postprandial states. Clin Sci (Lond). 1991;81(5):621-626.

37. Aguilo A, Tauler P, Pilar Guix M, et al. Effect of exercise intensity and training on antioxidants and cholesterol profile in cyclists. $J$ Nutr Biochem. 2003;14(6):319-325.
International Journal of General Medicine

\section{Publish your work in this journal}

The International Journal of General Medicine is an international, peer-reviewed open-access journal that focuses on general and internal medicine, pathogenesis, epidemiology, diagnosis, monitoring and treatment protocols. The journal is characterized by the rapid reporting of reviews, original research and clinical studies across all disease areas.

\section{Dovepress}

A key focus is the elucidation of disease processes and management protocols resulting in improved outcomes for the patient. The manuscript management system is completely online and includes a very quick and fair peer-review system. Visit http://www.dovepress.com/ testimonials.php to read real quotes from published authors. 